\title{
BUREAUCRATIC RATIONALISM AND THE QUIET (R)EVOLUTION
}

\author{
WILLIAM TWINING*
}

\author{
Marlene Le Brun and Richard Johnstone, The Quiet (R)evolution: Improving Student Learning in \\ Law, North Ryde, NSW, Law Book Company, 1994, pages i-lxxv, \\ 1-412. Price $\$ 60$ (softcover) \$45 (softcover at academic price direct from publisher) ISBN \\ 0455212791.
}

We do something called teaching. But we all know from bitter personal experience that nothing is, or can be, taught once we get beyond the communication to small children of the basic mysteries on which civilization depends how to read, how to write, how to count. We can of course pump students full of facts or even brainwash them but pumping facts is a waste of everybody's time and washing brains in public is, as Justice Holmes might have told us, dirty business. Learning is what students are there for and all we know about learning is that, on any level of complexity, it is every man for himself and by himself, imposing a perhaps delusive formal pattern on the swirling chaos by a prodigious effort of the individual will. It may be that we can stimulate, or irritate, an occasional student into undertaking this arduous task - but, if we do so, it will be much more by accident than by our own design. Karl Llewellyn once observed that the function of the law teacher is not to let the true light shine; he was wise to content himself with that negative formulation.

Grant Gilmore

At a recent conference on legal education I found myself on a panel discussing vocational training. A well-known clinician expressed the view that the objectives of skills courses should be framed in terms that are precise, objective and measurable. Knowing that I had expressed doubts about this position, ${ }^{2}$ the chairman invited me to comment. I said something like this: "I find the exercise of articulating learning objectives in the form of precise propositions a valuable discipline, especially in courses like jurisprudence — provided that you do not believe the propositions.” This elicited a ripple of applause, something so unusual from an audience of law teachers that I have been pondering its significance ever since. Had I won the support of educational Luddites? or did this response signal a deeper unease? Was this a display of sceptical attitudes similar to Gilmore's? I hope that my remark did not bring comfort to Luddites. There are some grounds for optimism, because they stay away from conferences about legal education. The quotation from Gilmore and my anecdote illustrate an ambivalence on the part of academic lawyers who take teaching seriously, but who are uneasy about some aspects of the current movement to introduce modern educational theory into legal education. Le Brun and Johnstone's The Quiet (R)evolution is likely to encounter a similar ambivalence. The purpose of this essay is to explore why this might be so. At the outset it is important to dispose of the Luddites. It would be easy to interpret Grant Gilmore's statement as either a counsel of despair or a rationalisation of laziness. ${ }^{3}$ My Janus-faced treatment of one orthodoxy in relation to learning objectives might also be used as an invitation not to think seriously about objectives at all. So let me make it clear that I believe that law teachers can learn a great deal from specialists in education and that Le Brun and Johnstone's The Quiet (R)evolution makes accessible some of the central ideas of relevant educational theory and best practice and applies them thoughtfully to the law school environment. ${ }^{4}$ What follows is controversial, the debate is among those who care about legal education.

The Quiet (R)evolution is an important pioneering book, advocating a "student-centered" approach to education. It grew out of experience of law teaching workshops or clinics pioneered in Canada and further developed in Australia since 1988. The book draws extensively on relevant general literature concerning educational theory and practice, as well as on the specific literature about legal education in many common law jurisdictions. The valuable bibliography fills almost fifty pages. The Quiet (R)evolution is clearly a 
substantial contribution and addresses many of the concerns of academic lawyers, but at the end one is left with a sense of unease that needs to be probed. The purpose of this review is to encourage present and intending law teachers to take it seriously, but to suggest how it might be improved in subsequent editions. If the tone is critical, the spirit of the criticism is constructive: this is an important work which has yet to realise its potential.

A critical review should at least start by assessing a work on its own terms. The Quiet (R)evolution is not easy to evaluate in this way, as its objectives are multiple and not as clear as they might be, perhaps because it is a mixture of educational theory, polemic, and practical manual. ${ }^{5}$ The primary objectives of the book might be restated as follows:

(1) To set current legal educational practice in the context of developments in higher education, legal education, and changing legal practice in Australia;

(2) To familiarise law teachers with relevant modern educational theory and with the range of available pedagogical techniques and methods of assessment that could be applied in undergraduate legal education and hence to help to bridge the gap between educational theory and law teaching practice at this level;

(3) To discuss critically issues relating to such matters as the formulation and use of general and particular learning objectives, evaluation of law degree programmes, and assessment of the performance of teachers and students in undergraduate legal education;

(4) To criticise one traditional model of law teaching and to advance an alternative model based on a conception of "good lawyering". (xiii).

The main intended audience is law teachers, in Australia and to a lesser extent in other common law jurisdictions. One major limitation that I shall discuss below is that the authors focus on single-subject undergraduate law degrees to the almost total exclusion of all other kinds of legal education. Within these parameters the book largely achieves its objectives. If its core is those parts which deal with (2) and (3), it ranks as a solid and competent review and application of a wide range of educational literature. It contains a wealth of information, analysis and practical advice, much of which is sensible. Clearly law teachers should be informed about educational theory and methods; this offers a convenient tool for their self-education. Objectives (1) and (4) are more problematic and most of my comments relate to these.

\section{SETTING THE CONTEXT: THE NATURE AND ROLE OF LAW SCHOOLS}

The authors quite rightly emphasise the importance of setting good legal educational practice in the context of developments in higher education, the legal education system, and legal practice. There are, no doubt, some special or unique features of the situation in Australia, but many of the relevant problems and trends are international, as the authors bring out in a stimulating closing chapter on future directions in "The face and form of legal education". However, the treatment of context is rather sketchy and the authors take a great deal for granted.

I run a seminar in London for present and intending law teachers. I regularly find that there is a tension between what the participants expect and want and what I insist on giving them in the first few weeks. Their demand is for specific classroom techniques; I refuse to move on to this narrow kind of "how" before exploring a number of questions about the whats and whys of legal education in a broad international context. My justification for asserting my authority as a teacher here is that I think it important to examine critically at the outset a number of deeply embedded assumptions that are prevalent in legal education discourse - in particular the beliefs that:

(i) most learning takes place in the classroom;

(ii) most legal education takes place in law schools;

(iii) law schools everywhere have and should have a shared mission (the football league model);

(iv) the core of that mission is primary legal education and that the term "law student" refers only to someone taking a first degree in law (the primary school image);

(v) the objective of primary legal education is to provide a basic education in law for intending private practitioners (the private practitioner image);

(vi) there is a common core of knowledge, skills and values shared by all "good private practitioners (the 
reductionist fallacy); and

(vii) law, by its nature, has the lowest unit costs of all subjects in higher education (the cheap subject fallacy). ${ }^{6}$ These assumptions have a direct bearing on the clientele of law schools, the objectives of particular programmes, the process of professional formation, the roles of academic lawyers, and what is involved in being a competent law teacher, inside and outside the classroom. For example, the suitability of particular techniques of teaching and assessment depend as much on the background and situation of the students as on the learning objectives of a programme or course.

Le Brun and Johnstone are not necessarily committed to all of these propositions - indeed they would reject some - but much of what they say fits this set of assumptions more comfortably than their converse. For most of the book they largely seem to take for granted (ii) to (vii) and their treatment of educational method is strongly oriented to the classroom - for example, they say almost nothing about mundane managerial aspects of teaching, such as ordering books for the library, liaising with bookstores, and obtaining copyright clearances.

Where they do address issues raised by questioning such assumptions, they tend to seek an easy way out from some recurrent dilemmas. For example, they finesse the well-worn academic/ vocational, education/training divide by arguing that their version of humane professionalism can reconcile the objectives of general liberal education and preparation for practice:

As we discuss in Chapter 2 and illustrate in Chapters 5 and 7, many of the skills and attitudes which are vocationally focused in fact provide an appropriate framework within which broader educational goals can best be achieved. By placing learning in a meaningful context, learning becomes relevant, and, thus, meaningful. ${ }^{7}$ Having neatly disposed of one of the main sources of difficulty, they are then free to focus on one form of legal education, viz. the first stage of professional formation of private practitioners. The next step is to follow current orthodoxy by postulating that an analysis of what constitutes "a good lawyer" can provide the foundation for prescribing the objectives, standards, and ideology of a sound basic legal education. Here they adopt a "client-centred model" of private practice: The model of lawyer which we advocate places the client at the centre of a process in which the client and lawyer actively participate in finding a solution which is acceptable to the client. (41).

They contrast this with:

the more traditional model in which the lawyer assumes responsibility and exercises predominant control and direction over the client's problems while the client remains a passive "recipient" of the lawyer's service." (ibid). ${ }^{8}$

To produce client-centred lawyers requires a mix of skills, dispositions, and attitudes that are best developed by "student-centred learning", a concept that I shall discuss below. Here one should note that some such monolithic model of "the good lawyer" is almost inevitably required by a form of educational theory in which the precise formulation of learning objectives is central and which, in extreme forms, requires that such objectives be SMART, (ie, specific, measurable, attainable, realistic, and time-bound) and that success is evaluated in terms of transparent performance indicators measuring outcomes. However, if not all lawyers are private practitioners, and if private practice is very varied, and if many or most students of law are not destined to become lawyers, what are reductionist models of "the good lawyer" doing as the basis for setting objectives in undergraduate legal education? ${ }^{9}$

By not exploring some of these basic assumptions before proceeding to consider questions of pedagogical method, the authors seem to be led into accepting an unnecessarily narrow, conservative, and monolithic view of the practices they seek to change and, perhaps more serious, they do not confront some of the dilemmas that pluralism poses for educators. Of course, not all of these assumptions are false or fallacious; some are embedded in the culture, and to a lesser extent the practice, of many law schools..$^{10}$ It is disappointing to find such views accepted unquestioningly in a book which purports to favour (R)evolution. However, there are certain advantages in focusing on one stage of one kind of primary education in one recognisable academic setting and, from now on, I shall proceed within something like the same framework of assumptions.

\section{TWO MODELS OF LAW TEACHING}

The authors' fourth objective is to criticise classical or traditional approaches to legal education and to advance an alternative. They tackle this by setting up two models of law teaching. What might be called the conventional model postulates a traditional isolated university setting and an established scientific body of 
knowledge; the role of the teacher is to transmit that knowledge and a limited range of analytical or other intellectual skills; the student is largely a note-taker and passive recipient of information from lectures and textbooks; the knowledge acquired is tested by unseen closed-book, examination.

Contrasted with this information-transmitting model is the facilitative model. The context is a supportive, stimulating, challenging, interdisciplinary learning environment; the objectives are set by a conception of "good lawyering" that is practical, reflective, client-centred, and ethical. This conception emphasises communication and connection between individuals; the focus is on active learning by students; the role of the teacher is to help to set clear learning objectives, to ensure that assessment fits these objectives, to act as a guide, facilitator and role model. Learning can be assisted by a wide range of techniques and resources and assessed by a variety of methods.

This bald summary suggests that what we have is a contrast between a caricature of the Dark Ages and a starry-eyed vision of a new Enlightenment, otherwise known as "humane professionalism". This would not be entirely fair to the authors, who acknowledge that some, rather uneven progress has been made away from the first model and who provide a wealth of detailed analysis and suggestions about both the means and the difficulties of moving towards the second. In any case, both are only ideal types and, sensibly, they do not claim that their vision is the only possible one.

Nevertheless, this way of posing the issues is misleading and dangerous. It is misleading because each ideal type contains an uneasy mixture of incompatible elements; it is dangerous because it gives support to an emerging orthodoxy which is not compatible either with the author's core values nor with a more pluralistic view of a healthy system of legal education.

The Dark Ages model can be quickly disposed of. It is a caricature of "traditional" university legal education: few law schools in the common law world approximate the model, except perhaps some oldstyle professional schools in which, ironically, judged by examination results as a performance indicator, dictated lecture notes have been a quite effective means of inducing parrot-learning. The model omits tutorials, which take many forms, but which most traditional university law schools in the United Kingdom (and many parts of the Commonwealth) have claimed are more important than lectures. Lectures are standardly used for purposes other than transmission of information; transmission of information in legal education need not be confined to black letter law; and black letter law was and remains the core of the Langdellian Socratic system ${ }^{11}$ - in short one should be careful not to conflate the conception of law as black letter rules involving some specific intellectual skills, transmission of information as contrasted with other educational objectives, and lectures and other methods and media of teaching. The mixes have been and are much more complex and varied than the model suggests. This point is important in the present context, not least because one senses that by choosing this particular target to attack the authors let all kinds of bad practices off the hook. Soft targets breed false polemics.

The first ideal type is too much like a caricature; the second is dangerously seductive. Who would not want their teaching to be deep, stimulating, sensitive, challenging, interdisciplinary, practical and ethical? Well, maybe some unenlightened students who wish to get through the hoops as quickly and painlessly as possible or others who want something different for whatever reason. But, if learning is to be studentcentred as legal practice is to be client-centred, then students should surely be able to control their own destinies. But maybe that is not quite what is meant by the rhetoric.

Let me illustrate this from personal experience as a student. I endured a classical education at a traditional English boarding-school. I loathed both the education and the school. The learning was "studentcentred" in three ways: first, we were under constant surveillance by a complex hierarchy of masters, monitors, mentors and other managers, mostly fellow pupils. Secondly, the process was almost entirely active learning: we prepared, we parsed, we translated orally and in writing, we constructed Greek and Latin compositions, we translated Latin poetry into English verse, we gave English renderings of the New Testament sight unseen from the Greek, and we developed techniques of survival and of playing the system. Thirdly, we were gradually made more and more responsible for our own learning. Two particular ways remain fresh in my memory: one holidays we had to "get up" from scratch the whole of The Odyssey and Book V1 of the Aeneid in anticipation of a test, involving commentary as well as translation, at the start of term. Second, the public examinations, then called School Certificate and Higher Certificate, were treated by the authorities as both an intrusion and a dilution of the pure stream of classical learning. So we were 
expected to do most of the preparation on our own. We were nevertheless expected not to let the school down by failing to get Distinctions in subjects in which we had received almost no instruction. I do not know whether this enforced self-education was inadvertent or deliberate or a bit of both. But we were clearly conforming to the expectations of Authority.

I chose to read law in order to escape from classics. At Oxford in the 1950s a somewhat different form of self-education was the predominant mode. Lectures were optional; reading-lists, when they existed, were deliberately long, so that we did not all read the same things; the main imperative, the weekly essay(s), was highly focused and related to only a small part of the syllabus; I had a total of four tutorials in Constitutional Law; college-based examinations, called collections, were held at the start of some terms: they provided one stimulus to study in vacations and a means of monitoring that we were doing some reading; we were advised "to read around the subject" and we were largely left to our own devices. During the first two years I was not particularly engaged with the subject and did rather little work; so during my final year I had to teach myself law almost from scratch in preparation for finals. ${ }^{12}$

I tell these stories mainly to illustrate some different conceptions of what such an approach can involve. For me "student-centred" carries associations of surveillance, drill, discipline and control imposed by teachers and other authoritarian figures on students; "self-education" on the other hand involves choice by the student of learning objectives, sources, methods and ideology. It can be stimulated or encouraged by non-m/paternalistic teachers; or by a supportive environment; or it can result from neglect, bad teaching, necessity, lack of access, or even just a strong desire to learn. Which of these meanings underlies The Quiet (R)evolution? "In this book we advocate a student-centred approach as that which appears most compatible with this conception of lawyering as an essentially relational and human activity. In order to implement this method we need to consider what happens in our classrooms from our students' standpoints." (43) ${ }^{13}$

The authors recognise that by producing a teachers' manual that advocates student-centred learning, "we skew the ideal approach.(xv) By this they appear to mean that by focusing on teacher-specific behaviour they are only dealing with one part of the process of education. But the "skewing" goes deeper than that. The term "student-centred learning" is a part of modern Ed-speak that is easily rumbled. It clearly means something different from "self-education", for something called "self-regulated learning" is said to be "[a]t the far end of the educational continuum, opposite teacher-dependent learning." (91) Less than a page is devoted to that extreme form of education and even this passage includes a sentence which starts: "Our job in developing student autonomy ...” Just before a section entitled "Towards a student-centred approach, Figure 2.5 lists 16 ways of promoting student-centred learning in law; fifteen of these start with "we" meaning teachers; they include "we set clear aims and objectives for learning" and "we create a climate for learning". (88) Throughout the book nearly all the active verbs apply to teachers, as is clearly illustrated by the table of contents: setting directions, designing assessment, structuring materials and classes, directing our efforts ... it is we, we, we all the way home. ${ }^{14}$ And presumably it is we who do the "centring".

Of course, this might be just a matter of style in a book addressed specifically to teachers. But the "skewing" also goes to substance. For example, it should not need a lot of high theory and empirical research to establish that the great bulk of learning in higher education, including formal legal education, takes place outside the classroom. The authors pay lip-service to this. However, when they come to discussing teaching methods and teaching devices almost all of the attention is centred on classroom activities. ${ }^{15}$ One important exception is what are variously referred to as "teaching materials" (248) and "instructional materials" (411), rather than learning materials. In one of the weakest sections in the book the authors assume that "we" design the materials and choose the cases and even the different "voices" that should be fed to the students.

Underlying this are what seem to me to be rather extreme forms of teacher control over objectives, subject-matter, source materials, methods, and even values. How can one explain this apparent contradiction between concern for student autonomy and self-education on the one hand and an equally strong latent $\mathrm{m} /$ paternalism on the other? Possible hypotheses include sheer hypocrisy, Machiavellian subtlety in preserving teacher power, or the confusion of the unreconstructed. While the authors are clearly concerned to reassure teachers that this approach does not really threaten their status, importance or power, ${ }^{16}$ they also seem to be genuinely committed to the autonomy of both clients and students. I would hypothesise that the central theme of this book is flawed by a tension between a genuine commitment to the 
autonomy of learners and a too-ready espousal of an emerging orthodoxy in legal education and training which, despite much of its rhetoric, is essentially a form of homogenising authoritarian bureaucraticrationalism.

Now I must be careful not to throw the baby out with the bath water. As Max Weber predicted, universities have become increasingly bureaucratized, ${ }^{17}$ so have courts and law firms. ${ }^{18}$ This is something we have to live with and adjust to: in any case, management consultants and bureaucrats are not wrong all of the time. As was suggested above, good teaching involves good management and careful preparation, including planning ahead, booking audio-visual equipment, ordering books six months in advance, and assisting the career development of colleagues, as well as being reasonably sophisticated about aims and objectives at various levels. So let us make some concessions:

First, I share with the authors the view that educational theory is important. Law teachers can learn much from educationalists and the general literature on education and it is part of their job to be familiar with the literature. The idea that teachers are born and not made is no more plausible than the pick-it-up theory of lawyering that would make a large part of the law teaching profession redundant.

Second, university teachers are rightly accountable to those who fund them, whether they be students, parents or the public purse and it seems inevitable that a degree of bureaucracy and compromise is necessary to make accountability work. The crudity of some of the early attempts to deal with this problem does not justify abandoning the enterprise.

Third, it would be strange to abandon completely the idea that learning, teaching, specific educational programmes, and educational institutions should be purposive and that different methods and techniques and other means of attaining particular goals, aims and objectives are subject to rational appraisal. Having a sense of direction is usually better than aimlessness. For an individual teacher formulating precise learning objectives, even in behavioural terms, can be a good discipline, provided that one does not interpret such formulations literally: in education as in other spheres we often know better than we speak and speak better than we know and much of what we are dealing with cannot be reduced to protocols or formulae. That said, one can agree that Gilmore probably overstated his case.

Fourth, those responsible for ensuring competence, whether they be the professions or other bodies, have a practical problem of assessing and policing it in order to protect the public. How to do this fairly and efficiently with a rapidly changing and increasingly fragmented profession is a genuine problem, which perhaps inevitably requires some artificial imposition of uniformity.

Fifth, it may be that the combination of cost-cutting and expansion in higher education has made the individualist humanism of Mark Hopkins or Gilbert Highet a hopelessly outdated, nostalgic dream, but some "traditional" teachers cling to that ideal. If so, the authors need to confront such traditionalists as well as Luddites and sceptics.

All that conceded, strong forms of bureaucratic rationalism threaten liberal values. The liberal educator has to be constantly on guard against over-precise formulation of objectives, homogenisation in the name of rationalisation, Orwellian Ed-speak, and evangelical forms of educational correctness. Anything subversive of free enquiry, curiosity, breadth of perspective, suspicion of dogma, and independence of thought needs to be treated with suspicion. The authors recognise this, but they do not adequately confront the tension between some of their basic values and the technocratic tendencies of much educational theory. ${ }^{19}$

So far I have criticised The Quiet (R)evolution on two main grounds: that it accepts uncritically a number of essentially conservative assumptions about the nature and potential of law schools; and that "student-centred learning" can be a euphemism for teacher-centred narcissism. Before making some constructive suggestions, let me touch briefly on one other matters of concern to law teachers.

\section{Law Teaching as a Vocation ${ }^{20}$}

The Quiet (R)evolution focuses mainly on pedagogy. It deals interestingly with some aspects of the difficulties of being a law teacher, but it does not develop a rounded picture of what it is to be a good professional. The prototypical fulltime academic lawyer needs to be equipped to be a lawyer, a scholar, a politician-administrator as well as an educator. ${ }^{21}$ These are all inter-related and affect the quality of pedagogy. The authors say remarkably little about the difficult relationships between teaching and research, teaching and practice, career development, and, most surprisingly, mastery of and enthusiasm for one's 
subject. Most contemporary academic lawyers are specialists and one needs to beware of reductionist models of "the law teacher" as one does of "the lawyer". However, there is a developing literature on academics in general and on law teachers in particular. ${ }^{22} \mathrm{~A}$ book devoted to the educational aspects of law as a discipline needs to say something in general terms about the roles, qualifications, qualities, training, career development, and dilemmas of those who choose to follow an academic career. One danger of emphasising the pedagogic aspects in isolation is that it may not allay suspicions that interest in educational theory is sometimes a substitute for specialist expertise, that teaching is seen to be in competition with research, and that genuine engagement in the subject-matter of one's discipline is not viewed as the most important attribute of a teacher in higher education.

\section{CONCLUSION}

I hope that there will be further editions of The Quiet (R)evolution. It is absolutely right to emphasise the importance of educational theory. It contains much of value and its faults and omissions are remediable. To make it into a first-rate book, some changes are needed. I would suggest the following:

First, and most important, its underlying assumptions about the nature and role of university law schools — or more broadly of formal legal education — need to be reviewed.

Secondly, if this leads to acceptance of a more pluralist vision of legal education, then the practical problems of educators in coping with diversity need to be faced at a number of levels. For example, how is a teacher to behave with a class of 150 learners from different backgrounds, with different personal agendas and various learning styles? How can one design a sensible vocational course for graduates from a pluralistic primary system who are destined to move into a fragmented and rapidly changing profession? ${ }^{23}$ To what extent do general educational theories and specific pedagogical techniques developed in respect of secondary schools and undergraduate education apply to other kinds of "student" in legal contexts? ${ }^{24}$ For example, are there specific skills and techniques that are particularly appropriate for continuing professional development or legal awareness programmes? And how does one challenge the get-wise-quick attitudes of busy practitioners or the anti-intellectualism of some undergraduates?

Thirdly, a more rounded picture of the roles, qualities, and career development of full-time career law teachers is needed.

Fourthly, ideological commitment to particular visions of legal theory, legal education and law practice need to be disentangled, so far as is feasible, from accounts of some of the transferable skills and resources that any competent teacher needs to master: using an overhead projector, ability to employ buzz groups and other devices judiciously, speaking audibly and assessing consistently are qualities required as much of a post-modernist teacher of company law as of a traditional family lawyer, or a committed teacher of mediation.

Fifthly, more needs to be said about law as a discipline. My personal view is that is a marvellous subject that has been institutionalised in ways which prevent it from realising its potential in all its diversity. Some of the authors' enthusiasm for educational theory could usefully be extended to the subject-matter of law.

Finally if this is to become the standard handbook for any law teacher who aspires to be a good professional, it needs to address not only the concerns of traditionalists, like Pat, but also of sceptics like Gilmore, and of those of us who believe in liberal education and enlightened vocationalism, yet are deeply suspicious of evangelising bureaucratic rationalism.

* Research Professor, Faculty of Laws, University College London. I am grateful to Terry Anderson, John Wade and Jack Goldring for helpful comments on an early draft of this article. (C)1997. (1996) 7 Legal Educ Rev 291.

1 Quoted in an obituary of Gilmore in (1982) 28 U Chi L Sch Rec 43, without further citation.

2 W Twining, Law in Context: Enlarging a Discipline (Oxford: Clarendon Press, 1997) ch 10.

3 I have borrowed the phrasing from John Wade (letter to the author).

4 The brackets in the title, which may irritate and distract some readers, have been omitted in the rest of the text.

5 Despite attempts to liven the text, it has the feel of a manual. One reviewer has observed that it is rather similar in form to the kind of legal textbook that fails to stimulate the active learning that the authors advocate: A Zariski, The Quiet (R)evolution: Improving Student Learning in Law (1995) $45 \mathrm{~J}$ Legal Educ 309, at 310. This criticism, though harsh, is borne out by my experience in using The Quiet (R)evolution in a seminar for intending law teachers, who found it worthy but dull. To some extent this is a matter of style that can be rectified in later editions; but there may be a more fundamental tension between the aspiration to make learning interesting and enjoyable and the rational bureaucratic underpinnings of much fashionable educational theory. 
6 Compare the recent report on Legal Education in Xanadu which is based on a contrasting set of assumptions:

In (almost) all societies:

(i) Almost everyone receives some legal education.

(ii) That process lasts from cradle to grave.

(iii) The amount of informal legal education (i.e. outside educational programmes) greatly exceeds the amount of formal legal education, even for career lawyers.

(iv) The actual and potential demand for formal legal education almost invariably exceeds the supply.

(v) Most formal legal education is delivered in institutions other than law schools.

(vi) Within most countries, there are specialised institutions called law schools that can be quite varied. For example, they vary within and between countries in respect of wealth; size; manifest and latent functions; prestige and influence; the age, class, and gender of students, faculty and other staff; academic standards; conceptions of scholarship; and even architecture.

(vii) The culture of law schools is to some extent international within legal traditions or families, but it is also much influenced by local historical, economic, ideological, and other factors, including the structure and financing of higher education, distributions of power and authority, and the nature of the legal system and the legal profession."

This report is discussed in Twining, supra note 2, ch 15 and, in respect of the United States, in W Twining, Rethinking Law Schools (1996) 21 L \& Soc Inquiry 1007.

7 I have a good deal of sympathy for the proposition that the Le Brun- Johnstone model of preparation for private practice could indeed provide one good form of liberal legal education (despite the question begging use of "relevant"). However, law is sufficiently rich as a subject-matter of study to be an excellent vehicle for furthering "liberal" educational values in a variety of other settings. See generally, W Twining, Blackstone's Tower: The English Law School (London: Sweet \& Maxwell, 1994). In a more than generous review of this book Professor Goldring takes me to task for saying almost nothing about teaching methods and student learning: J Goldring, Cultural Cringe or Lessons for Australian Legal Education?, (1996) 7 Legal Educ Rev, 125. This is fair comment. In mitigation, I would plead that I was reacting against a tendency of discussions of legal education to ignore or downplay the culture and infrastructure of law schools as institutions and what is involved in ideas of legal scholarship. I also felt that I had written rather too much about legal education elsewhere. However, I probably over-reacted and there is plenty of scope for further accounts of student learning at Rutland both inside and outside the classroom.

8 Le Brun and Johnstone link this reductionist image of the private practitioner to a more controversial model of "tender-minded lawyering” which they explicitly attribute to critical legal studies: "In perhaps an idealised conception, this new breed of lawyer remains aware that they are human beings with strengths, weaknesses, and doubts as well as convictions... The model can adopt a number of alternative demeanours: 'There is the environmental [lawyer's] vision of a country who takes her resources and her unborn citizens seriously enough to take good care of the earth. There is the feminist [lawyer's] vision of a country whose laws do not allow women to be beaten with impunity, ...There is the critical [lawyer's] vision of a country whose laws enforce the substantive imperatives ... of racial equality ...' “ (42). However attractive it may be for some lawyers, this ideological element has a further narrowing function: we now seem to have a book dealing only with the initial stage of professional formation for one kind of private practitioner who has a particular set of ideological commitments and, semble, individual rather than corporate clients. This sounds like a narrow orthodoxy rather than an approach which accepts pluralism in respect of legal education, legal practice and the personal values of individual lawyers .

9 See Twining, supra note 2, ch 16 (discussing Kronman's “lawyer-statesman” and other reductionist models of “the lawyer”).

10 In my experience the practice of law schools often outruns their discourse and self-image. For example, most law schools in fact provide educational services to a quite varied clientele - continuing professional development for lawyers and others, postgraduate courses, short courses for administrators or health officials, legal awareness programmes, access courses, human rights for school teachers. Yet how many of the recipients of these services are treated as "students" for purposes of assessing staffstudent ratios, or teaching loads, or representation on faculty committees, or, perhaps most important, orthodox discussions of "legal education"?

11 At 19-21 the authors give a potted history of common law education and at points distinguish between Langdell's conception of legal science and the educational objective of thinking like a lawyer in the narrow sense. But later they reiterate that "The lecture is based on the assumption that teaching involves an expert lecturer giving pre-packaged knowledge to students.” (258) Some of the sensible advice they give on how to lecture contradicts this.

12 Le Brun and Johnstone's depiction of the Oxbridge system as one "in which the teacher assumes the central role in teaching” (37) is either a meaningless tautology or quite contrary to my experience, which was fairly typical for the period. Tutors had the facilitative, guiding role that they favour, but left undergraduates to their own devices much more than would be allowed by the highly structured form of teaching advocated by the authors. I rebelled against my classical education because of its authoritarian style; I learned a good deal despite myself, but the process was inhumane. I rebelled against my primary legal education not because of the learning environment, which was excellent, but because of the predominant conception of law as a subject of study and as a phenomenon. Part of my dissent from The Quiet (R)evolution is that it too readily associates narrow, black letter approaches with passive learning and in their enthusiasm for a rational-bureaucratic approach to professional formation the authors appear to espouse a latent authoritarianism which is the more powerful for being "quiet".

13 Italics added. On the next page the following purple passage further exemplifies the tendency:

If we want our students to learn the importance of "fellow-feeling" ... we must construct learning experiences in which we model reflection and deliberation in action (Schon, 1987). If we want our students to think beyond the "box" of law (Neave, 1990), we cannot continue to treat them as empty shells. If we wish to imbue notions of justice and fairness in our students, which we argue is part of our work as law teachers, we need to make the vocabulary of justice, liberty, truth, and law part of our daily language as professionals. (44)

14 Even in respect of "Peer Tutoring, Peer Learning, and Co-operative Learning”, the authors feel it necessary to add the following reassurance: "We as teachers have a vital role in all of these peer learning methods - setting and clarifying objectives, preparing materials, structuring activities, negotiating ground rules, monitoring progress, and intervening to remedy problems that may arise." (293-94) Why not let them just got on with it?

15 See the index headings for Teaching Devices and Teaching methods at 411.

16 See, for example, the rather feeble passage on self-effacement at 293-4. The logic of self-education leads to the view that teachers are just one kind of learning aid and that learning to play that role judiciously is central to good teaching, especially in higher education.

17 M Weber, “Science as Vocation” (From Max Weber: Essays in Sociology trs. H Gerth, \& C Wright Mills, New York, 1946).

18 A Kronman, The Lost Lawyer (Cambridge, Ma: Harvard University Press, 1993).

19 For example, some of the criticisms of the Bloom-Mager orthodoxy in respect of objectives are noted at 157-8, but are not really 
answered. This is a set of issues that could benefit from more extended treatment in future editions.

20 Pessimists may interpret this as echoing Weber, supra note 17.

21 International Legal Center, Legal Education in a Changing World (New York: International Legal Center, 1975) 76-82, discussed in W Twining, The Law Teacher as Superstar, Academic Law and Legal Development (Lagos: University of Lagos, 1976).

22 AH Halsey, Decline of Donnish Dominion (Oxford: Clarendon Press, 1992); T Becher, Academic Tribes and Territories (Bristol, PA.: Open University Press, 1989); P Leighton, T Mortimer, \& N Whatley, Today's Law Teachers: Lawyers or Academics? (London: Cavendish, 1995); Twining, supra note 7, passim.

23 This has been a central concern of the Lord Chancellor's Advisory Committee on Legal Education and Conduct (ACLEC) in their recent review of legal education in England and Wales. See now ACLEC, First Reprint on Legal Education and Training (London: ACLEC, 1996).

24 On who are "law students", see supra notes 6, 10. 